\title{
Pediatric Neurotoxicity of Anesthetic Agents: Are We too Worried or too Little?
}

\author{
Rashmi Bhatt ${ }^{1} \quad$ Puneet Khanna' \\ ${ }^{1}$ Department of Anaesthesiology, Pain Medicine and Critical Care, \\ AllMS, New Delhi, India
}

\begin{abstract}
Address for correspondence Puneet Khanna, MD, E-141, Second Floor,
\end{abstract} G K II, New Delhi 110 048, India (e-mail: k.punit@yahoo.com).

J Neuroanaesthesiol Crit Care 2018;5:3-7.

\author{
Abstract \\ Keywords \\ - anesthetic agents \\ - neonates and infants \\ - neurocognition \\ - neurotoxicity
}

The debate on possible neurocognitive adverse effects of anesthetic agents refuses to cease. As evidence builds up, both for and against the debate, a conclusion evades us. More human studies on the subject have now been carried out, and yet we do not have a consensus. In this review, we attempt to relook at the existing evidence, as well as examine some new information as we pursue a greater understanding of this complex matter.

\section{Introduction}

Until a few years ago, the only questions that worried parents of children undergoing surgery, would ask were about the risks of surgery. More than the implied safety of the anesthetic procedures, it was the apparent insignificance of their contribution to the risk. Anesthesia was believed to be too simple to pose any significant danger both to the short term as well as long-term outcome. Millions of children undergo various surgical procedures, every year across the world. As anesthesia practice has evolved, we have newer drugs with better safety profiles, and yet much remains unknown about their adverse effects. Probably, one of the most debated controversies of the last decade is the possibility of adverse neurocognitive effects of commonly used anesthetic agents. The fact, that such effects have been associated with agents which have long been in use and remain so today is of much concern as it puts a large number of children at risk. ${ }^{1}$ Much research is now available on animal and human studies to investigate potential neurotoxicity of anesthetic agents. We have enumerated the key human studies, which were reviewed for the purpose of this article (-Table $\mathbf{1}$ ).

\section{What Do We Know?}

Agents such as ketamine, benzodiazepines and inhalational agents have been a part of anesthetic practice for decades. It was for the first time in 1999 that Ikonomidou et al. cast a shadow of doubt by bringing to light their observation. ${ }^{10}$ For the first time, there was concrete evidence of undesirable neurotoxic effects of anesthetic agents on the brain, albeit rodent brain. Although till date we do not have a consensus to the debate, yet the evidence, both for and against the argument is increasing, probably taking us closer to the facts.

While on the one hand, physicians across the world are attempting to minimize maternal exposure to drugs and environmental factors to prevent adverse foetal neurological outcomes, the likelihood of anesthetic neurotoxicity is worrisome. As is now widely acknowledged that neuronal synaptogenesis continues well into early childhood, the implications of increased anesthetic exposures to paediatric patients could be serious, especially in neonates and infants. ${ }^{11}$ The data available from animal studies has certainly changed the way we look at paediatric anesthesia.

Most of the preclinical research data come from work on the rodent and primate brain. Not all anesthetic agents have been used in these studies. Ketamine was one of the first drugs to be studied. Its use in dose range of $20-50 \mathrm{mg} / \mathrm{kg}$ for up to $24 \mathrm{~h}$ demonstrated widespread neuroapoptosis in rat brain. ${ }^{10}$ Diazepam administration was associated with cell degeneration in parietal cortex and laterodorsal thalamus in the same species. ${ }^{12}$ These effects were more prominent with the repeated and prolonged administration of the agents. Other agents have been used like ethanol and antiepileptic agents which have a similar mechanism of action. ${ }^{13}$ To replicate clinical situations, researchers used various combination of anesthetic agents, similar to those in clinical practice, though in much lower doses. The use of midazol$\mathrm{am}$, isoflurane and nitrous oxide, together for $6 \mathrm{~h}$ resulted in apoptotic neurodegeneration along with memory and learning impairment in rats. ${ }^{14}$

Copyright $\odot 2018$ Indian Society of Neuroanaesthesiology and Critical Care
License terms

(9) (1) $\ominus \circledast$ 
Table 1 An overview of significant human studies on anesthetic neurotoxicity

\begin{tabular}{|c|c|c|c|c|}
\hline Authors & Year & $\begin{array}{l}\text { Age at exposure } \\
\text { studied }\end{array}$ & Study design & Outcome and inferences \\
\hline Rozé et $\mathrm{al}^{2}$ & 2008 & $<33$ wks & $\begin{array}{l}\text { Prospective, population based } \\
\text { Exposure to sedatives including } \\
\text { opioids }\end{array}$ & $\begin{array}{l}\text { No association of prolonged sedation with } \\
\text { adverse outcome }\end{array}$ \\
\hline Kalkman et $\mathrm{al}^{3}$ & 2009 & $<2 \mathrm{y}$ & $\begin{array}{l}\text { Retrospective cohort Exposure } \\
\text { to inhalational agents, fentanyl, } \\
\text { sufentanil }\end{array}$ & $\begin{array}{l}\text { No confirmation of any effect, underpow- } \\
\text { ered study }\end{array}$ \\
\hline Barrels et $\mathrm{al}^{4}$ & 2009 & $<3 y$ & $\begin{array}{l}\text { Monozygotic } \\
\text { concordant-discordant twin } \\
\text { study } \\
\text { Early versus late exposure } \\
\text { compared }\end{array}$ & $\begin{array}{l}\text { No observed differences between exposed } \\
\text { and unexposed twin }\end{array}$ \\
\hline Guerra et al ${ }^{5}$ & 2011 & $<6$ wks & $\begin{array}{l}\text { Prospective postoperative } \\
\text { follow-up in cardiac surgery } \\
\text { Exposure to inhalational agents, } \\
\text { opioids, benzodiazepines, } \\
\text { ketamine }\end{array}$ & $\begin{array}{l}\text { No association between anesthetic expo- } \\
\text { sure and neurodevelopment }\end{array}$ \\
\hline DiMaggio et $a^{6}$ & 2011 & $<3 y$ & $\begin{array}{l}\text { Retrospective sibling birth } \\
\text { cohort design }\end{array}$ & $\begin{array}{l}\text { Risk of diagnosis higher in exposed group } \\
\text { but no causal connection }\end{array}$ \\
\hline Flick et $\mathrm{al}^{7}$ & 2011 & $<2 \mathrm{y}$ & $\begin{array}{l}\text { Retrospective matched cohort } \\
\text { study } \\
\text { Compared single versus } \\
\text { multiple anesthesia exposures } \\
\text { to halothane and nitrous oxide }\end{array}$ & $\begin{array}{l}\text { Increased risk for a learning disability with } \\
\text { multiple exposures }\end{array}$ \\
\hline Sun et $\mathrm{al}^{8}$ & 2012 & $<3 y$ & $\begin{array}{l}\text { Sibling-matched cohort study } \\
\text { Exposure to inhaled agents }\end{array}$ & $\begin{array}{l}\text { No risk found with single exposure in } \\
\text { healthy children }\end{array}$ \\
\hline Yazar et al ${ }^{9}$ & 2016 & $<3$ y & Cohort study & $\begin{array}{l}\text { No association between anesthesia expo- } \\
\text { sure and myopia, reduced visual acuity or } \\
\text { retinal nerve thinning }\end{array}$ \\
\hline
\end{tabular}

Alarmingly, the use of isoflurane alone for $1 \mathrm{~h}$ and at MAC values $<1$ was also seen to produce significant changes. ${ }^{15}$ The use of sevoflurane and propofol is also not entirely safe. Their use in rodents was also seen to result apoptotic neurodegeneration. ${ }^{16}$ Most of these effects were observed to occur in the first 1-2 weeks of life in these animals, which was the period of peak synaptic generation activity. Furthermore, these changes could be identified in multiple areas of the brain including, the cortex, thalami, hippocampus basal ganglia as well as the spinal cord. Non-rodent studies carried out in piglets and monkeys have also led to similar derivations, with those on the piglet brain being of particular relevance as it closely resembles the human brain with respect to development and myelination. ${ }^{17}$

The proposed mechanism of this anesthetic neurotoxicity is a reduced synaptic activity due to a reduction in trophic factors. This leads to initiation of the apoptotic pathways in the postsynaptic neurons, through both intrinsic and extrinsic pathways leading to cell death. ${ }^{18}$ The anesthesia-induced synaptic suppression is believed to be the cause of decreased synthesis of brain derived neurotrophin factor, thereby promoting cell death. The precise mechanism of suppression of synaptic signalling by anesthetic agents is unknown, but effects on synaptic transmission of glutamate and GABA are believed to be responsible. This is further corroborated by the apoptotic effects observed with use of GABAergic drugs such as midazolam, propofol, thiopentone and volatile anesthetics. ${ }^{19}$ The extrinsic pathway of apoptotic initiation is also believed to contribute to anesthetic neurotoxicity, seen with ketamine, propofol and isoflurane, by the suppression of prosurvival extracellular-related kinase signalling. Lithium and dexmedetomidine are believed to be neuroprotective by interefering in this pathway. Several anesthetic agents have been found to exert an anti-inflammatory effect in adults whereas a pro inflammatory effect is seen at a younger age. This is also believed to add to the inflammatory insult caused by surgery and pain. The pattern of neuronal injury also appears to be heterogeneous. The cholinergic neurons appear to be most resistant to neuronal injury, and since anesthesia has been shown to cause cholinergic suppression, it appears to increase the susceptibility of the cells to cell death. Anesthetics induced seizure activity has also been proposed as a mechanism, though no electroencephalogram verification of the same has been seen. Pre-existing hypoxic or ischemic damage to the brain neurons has been observed to increase the vulnerability of neurons to apoptosis. ${ }^{20}$ This observation puts neonates with even mild hypoxic injury at increased risk of neurotoxicity, thereby affecting their long-term neurological outcome significantly. 


\section{Do We Know Enough?}

Despite concrete evidence available from preclinical studies, its extrapolation to and interpretation in human subjects has proved to be far more difficult. A prospective, controlled randomized trial would be a litmus test for the proposed theories and observations of the animal studies. Herein, lies the difficulty: both ethical and practical. The application of animal research to human subjects is rarely straightforward, but the study of anesthetic neurotoxicity has been one of the biggest challenges of recent times. The ethical challenge lies in drawing up the control group, the practical in follow-up. A true control would be a child who would not receive anesthesia for surgery which is an unacceptable proposition. Neither would it be ethical to prevent this child from undergoing surgery. No procedure in the paediatric population is truly an elective one. Any surgery deferred in the present carries consequences if postponed indefinitely. Many surgeries like hernia repair can definitely be scheduled beyond the most active synaptogenetic phase, but do require eventual correction. Which brings us to the next challenging aspect. Despite several hypothesis, it is not really known as to what age the human brain remains susceptible to neurotoxic effects of anesthetic agents. The vulnerable period in animal brain does not correlate accurately with human neurodevelopment. What is known, by limited research and consensus is that the intrauterine period as well as early childhood is the most likely to be affected. ${ }^{21}$ Most anesthetists would like to defer procedures like hernia repair to beyond 3 years of age, but dilemma arises for procedures whose correction bears importance on neurological as well as psychological correction. These include hypospadias repair, cleft lip and palate surgery, cochlear implant, etc.

Another problem arises with respect to the doses of the anesthetic drugs used in animal studies. It is well-known that dose requirements of these drugs in animal groups is much higher, varying even across the species. Since the clinically used doses are much lower, the safety margin is difficult to estimate, and the safety can never be established entirely. Although repeated exposure to anesthetic drugs is a definite risk factor but precisely how much is too much cannot be determined.

A prospective study entails prolonged periods of follow-up for evaluation with no well-defined end points. It is difficult to know at what age the neurobehavioural changes will start manifesting, and beyond what age can we expect no new changes, to allow the end of follow-up. Hence, the exact period of observation is difficult to draw up. This makes these studies long, tedious and likely to miss out on causative association. The PANDA and the GAS studies are two early significant prospective studies whose observations were made available. ${ }^{22}$

Hence, the alternative remains retrospective observational cohort studies, many of which have in fact been carried out, though with drawbacks of their own. The biggest problem is of the confounding factors. Neurobehavioural development is a complex phenomenon which continues to baffle neuroscientists. It incorporates a complex interplay of socioeconomic, environmental and genetic factors which can alter behaviour and cognition, at multiple stages in life. Most epidemiologists now believe adolescence to be a just as important a phase in neurodevelopment as early childhood. The effect of these factors can never be entirely eliminated, even in cohorts of sibling pairs or twin pairs. A Dutch twin study carried out in 2009 by Bartels et al. failed to demonstrate any difference in school performance among pair of twins receiving anesthesia exposure selectively. ${ }^{4}$ Similarly, the PANDA study using sibling pairs with differential anesthesia exposure failed to establish any difference in the intelligence quotient (IQ) scores of these pairs. ${ }^{8}$ Glatz et al. in 2016, concluded from a Swedish national cohort that surgical and anesthetic exposure before 4 years of age bore minimal effect on cognitive performance. Despite several children receiving multiple anesthetic exposures, the academic achievements were more significantly affected by other factors, especially environmental. ${ }^{23}$

Large cohort studies can adjust for some of the confounding factors, but some unknown factors always exist, which preclude the establishment of causation and association. In addition, factors like variable frequency and duration of anesthetic exposures also make it difficult to draw clinically relevant conclusions. Some of the anesthetic agents such as midazolam and ketamine find use in the paediatric intensive care units, where their prolonged use could be a matter of concern. On the one hand, a Cochrane review has found some evidence of an adverse short-term outcome with a prolonged midazolam infusion use in neonates, on the other hand, the EPIPHAGE cohort study failed to establish any association between sedation exposure and outcome. .,24 $^{2}$

At the core of our understanding of neurobehavioural changes lies the use of assessment tools such as IQ score, mental scores and assessment methods for developmental delay. These are difficult to apply and interpret in very young children and can be reliably used only in the school going population. Hence, subtle changes in behaviour at early age may, in fact, be missed. Conversely, broad investigational batteries may, in fact, find associations, purely by chance and lead to fallacious results. All these factors result in even clinical studies being inconclusive.

\section{So Is it all Bad?}

So what does all the discussion and contention lead us to. We definitely do not have a conclusion, neither can we refute the evidence before us nor can we confirm it. Enough has been stated about the noxious effects of the anesthetic agents on neurodevelopment. We must however not overlook the accumulating data in favour of several anesthetic agents which have a potential to protect against anesthetic neurotoxicity. Of much interest is the class of alpha-2 adrenergic agonists which includes clonidine and dexmedetomidine. These have been observed to reduce anesthetic induced neuroapoptosis and cognitive diminution, particularly the one induced by isoflurane. ${ }^{25}$ Clonidine has been observed to protect against ketamine neuroapoptosis and resultant behavioural changes. Both of these drugs have not been found to possess any apoptotic effects by themselves. Another drug to have captured 
interest is xenon. In itself, it is minimally toxic but is effective against isoflurane-induced apoptosis. Being an N-methyl-D-aspartate antagonist, it is similar to ketamine in its mechanism of action but does not share its neurotoxic profile. ${ }^{20}$ Its cost and availability constraints do limit its use, but the neuroprotection is promising.

Free radical scavengers such as melatonin and estradiol, which are also anti-inflammatory, have also been found to prevent anesthetic and anti-epileptic-induced neurotoxicity. ${ }^{26}$ Other agents which are extensively being examined for their neuroprotective properties are lithium, hypothermia, L carnitine, bumetanide and erythropoietin. ${ }^{27}$

Neonatal pain, induced by surgery, is known to induce long-term behavioural effects in animals and humans, emphasising the need for adequate analgesia in the perioperative period. ${ }^{28}$ The impact of surgery, in addition to anesthesia, on perinatal brain injury also requires further investigation as inflammatory stimulation could exacerbate pre-existing hypoxic-ischemic injury. Surgery induces significant pain and inflammation that might worsen the toxic injury of hypoxia-ischemia by augmenting neuronal activity. ${ }^{29}$ In children undergoing surgery, anesthesia and analgesia serve to partly reduce adverse metabolic, immunological and humoral responses of surgery and pain. So, in fact, these protective effects can improve outcome in critically ill neonates and infants. ${ }^{30,31}$

Regional anesthesia is an important component of anesthetic plan, even in the paediatric population. The feasibility of awake regional anesthesia in neonates, especially pre-term neonates, offers dual advantage of avoiding general anesthesia as well as postoperative apnoeic episodes. ${ }^{32}$ However, it requires much expertise and finds limited use in abdominal and thoracic procedures.

\section{The Final Word}

There are numerous questions and controversies that remain unanswered as the clinical relevance of the enormous preclinical evidence of neurotoxicity continues to evade us. SmartTots is a collaborative effort of the International Anesthesia Research Society, the U.S. Food and Drug Administration and many others who are working to make anesthesia safer for infants and children. It is a multi-year collaborative effort designed to research the subject as well as provide information to those who seek it. It remains to be seen whether neuroprotective agents, effective in rodents, can provide clinical protection, and more importantly is anesthesia as detrimental as it appears to be? We are a long way from clinical trials of these apparent neuroprotective agents. The need for more prospective studies and translational research cannot be emphasised enough. The search for better evaluation of neuronal injury has already led us to biomarkers and micro-positron emission tomography imaging techniques to accurately detect sensitive and quantitative three dimensional molecular information from the brain. ${ }^{26}$ For now, it seems agreeable and rational to minimize anesthetic exposure for procedures which cannot be delayed and to ensure the safest standards of care.

\section{Funding}

None.

\section{Conflict of interest}

None.

\section{References}

1 Vutskits L, Davis PJ, Hansen TG. Anesthetics and the developing brain: Time for a change in practice? A pro/con debate. Paediatr Anaesth 2012;22:973-980

2 Rozé JC, Denizot S, Carbajal R, Ancel PY, Kaminski M, Arnaud C, et al. Prolonged sedation and/or analgesia and 5-year neurodevelopment outcome in very preterm infants: Results from the EPIPAGE cohort. Arch Pediatr Adolesc Med 2008;162:728-733

3 Kalkman CJ, Peelen L, Moons KG, Veenhuizen M, Bruens M, Sinnema G, et al. Behavior and development in children and age at the time of first anesthetic exposure. Anesthesiology 2009;110:805-812

4 Bartels M, Althoff RR, Boomsma DI. Anesthesia and cognitive performance in children: No evidence for a causal relationship. Twin Res Hum Genet 2009;12:246-253

5 Guerra GG, Robertson CM, Alton GY, Joffe AR, Cave DA, Dinu IA, et al. Neurodevelopmental outcome following exposure to sedative and analgesic drugs for complex cardiac surgery in infancy. Paediatr Anaesth 2011;21:932-941

6 DiMaggio C, Sun LS, Li G. Early childhood exposure to anesthesia and risk of developmental and behavioral disorders in a sibling birth cohort. Anesth Analg 2011;113:1143-1151

7 Flick RP, Katusic SK, Colligan RC, Wilder RT, Voigt RG, Olson $\mathrm{MD}$, et al. Cognitive and behavioral outcomes after early exposure to anesthesia and surgery. Pediatrics 2011;128:e 1053-e1061

8 Sun LS, Li G, DiMaggio CJ, Byrne MW, Ing C, Miller TL, et al. Feasibility and pilot study of the Pediatric Anesthesia NeuroDevelopment Assessment (PANDA) project. J Neurosurg Anesthesiol 2012;24:382-388

9 Yazar S, Hewitt AW, Forward H, Jacques A, Ing C, von Ungern-Sternberg BS, et al. Early Anesthesia Exposure and the Effect on Visual Acuity, Refractive Error, and Retinal Nerve Fiber Layer Thickness of Young AdultsJ Pediatr. 2016;169:256-259. e1

10 Ikonomidou C, Bosch F, Miksa M, Bittigau P, Vöckler J, Dikranian $\mathrm{K}$, et al. Blockade of NMDA receptors and apoptotic neurodegeneration in the developing brain. Science 1999;283:70-74

11 Mellon RD, Simone AF, Rappaport BA. Use of anesthetic agents in neonates and young children. Anesth Analg 2007;104:509-520

12 Ikonomidou C, Bittigau P, Ishimaru MJ, Wozniak DF, Koch C, Genz K, et al. Ethanol-induced apoptotic neurodegeneration and fetal alcohol syndrome. Science 2000;287:1056-1060

13 Bittigau P, Sifringer M, Genz K, Reith E, Pospischil D, Govindarajalu S, et al. Antiepileptic drugs and apoptotic neurodegeneration in the developing brain. Proc Natl Acad Sci U S A 2002;99:15089-15094

14 Jevtovic-Todorovic V, Hartman RE, Izumi Y, Benshoff ND, Dikranian $\mathrm{K}$, Zorumski $\mathrm{CF}$, et al. Early exposure to common anesthetic agents causes widespread neurodegeneration in the developing rat brain and persistent learning deficits. J Neurosci 2003;23:876-882

15 Johnson SA, Young C, Olney JW. Isoflurane-induced neuroapoptosis in the developing brain of nonhypoglycemic mice. J Neurosurg Anesthesiol 2008;20:21-28

16 Fredriksson A, Pontén E, Gordh T, Eriksson P. Neonatal exposure to a combination of $\mathrm{N}$-methyl-D-aspartate and gamma-aminobutyric acid type $\mathrm{A}$ receptor anesthetic agents potentiates apoptotic neurodegeneration and persistent behavioral deficits. Anesthesiology 2007;107:427-436 
17 Rizzi S, Ori C, Jevtovic-Todorovic V. Timing versus duration: Determinants of anesthesia-induced developmental apoptosis in the young mammalian brain. Ann N Y Acad Sci 2010;1199:43-51

18 Yon JH, Daniel-Johnson J, Carter LB, Jevtovic-Todorovic V. Anesthesia induces neuronal cell death in the developing rat brain via the intrinsic and extrinsic apoptotic pathways. Neuroscience 2005; $135: 815-827$

19 Sanders RD, Ma D, Brooks P, Maze M. Balancing paediatric anaesthesia: Preclinical insights into analgesia, hypnosis, neuroprotection, and neurotoxicity. Br J Anaesth 2008;101:597-609

20 Shu Y, Patel SM, Pac-Soo C, Fidalgo AR, Wan Y, Maze M, et al. Xenon pretreatment attenuates anesthetic-induced apoptosis in the developing brain in comparison with nitrous oxide and hypoxia. Anesthesiology 2010;113:360-368

21 Davidson AJ, Becke K, de Graaff J, Giribaldi G, Habre W, Hansen $\mathrm{T}$, et al. Anesthesia and the developing brain: A way forward for clinical research. Paediatr Anaesth 2015;25:447-452

22 Hansen TG, Engelhardt T, Weiss M. The relevance of anesthetic drug-induced neurotoxicity. JAMA Pediatr 2017;171:e163481

23 Glatz P, Sandin RH, Pedersen NL, Bonamy AE, Eriksson LI, Granath FN. Academic performance after anesthesia and surgery during childhood: A large-scale nation-wide study. Anesth Analg 2015;120:S289

$24 \mathrm{Ng} \mathrm{E}$, Taddio A, Ohlsson A. Intravenous midazolam infusion for sedation of infants in the neonatal Intensive Care Unit. Cochrane Database Syst Rev 2017;1:CD002052 doi: 10.1002/14651858.CD002052.pub2
25 Sanders RD, Xu J, Shu Y, Januszewski A, Haider S, Fidalgo A, et al. Dexmedetomidine attenuates isoflurane-induced neurocognitive impairment in neonatal rats. Anesthesiology 2009;110:1077-1085

26 Yon JH, Carter LB, Reiter RJ, Jevtovic-Todorovic V. Melatonin reduces the severity of anesthesia-induced apoptotic neurodegeneration in the developing rat brain. Neurobiol Dis 2006;21:522-530

27 Straiko MM, Young C, Cattano D, Creeley CE, Wang H, Smith DJ, et al. Lithium protects against anesthesia-induced developmental neuroapoptosis. Anesthesiology 2009;110:862-868

28 Walker K, Holland AJ, Winlaw D, Sherwood M, Badawi N. Neurodevelopmental outcomes and surgery in neonates. J Paediatr Child Health 2006;42:749-751

29 Sanders RD, Hassell J, Davidson AJ, Robertson NJ, Ma D. Impact of anaesthetics and surgery on neurodevelopment: An update. Br J Anaesth 2013;110 Suppl 1:i53-172

30 Sanders RD, Manning HJ, Robertson NJ, Ma D, Edwards AD, Hagberg $\mathrm{H}$, et al. Preconditioning and postinsult therapies for perinatal hypoxic-ischemic injury at term. Anesthesiology 2010;113:233-249

31 Zhang X, Liu F, Slikker W Jr., Wang C, Paule MG. Minimally invasive biomarkers of general anesthetic-induced developmental neurotoxicity. Neurotoxicol Teratol 2017;60:95-101

32 Morton NS. Local and regional anaesthesia in infants. Continuing education in anaesthesia. Critical Care and Pain 2004;4(5):169-171 